Check for updates

Cite this: RSC Adv., 2019, 9, 5620

Received 7th August 2018

Accepted 25th January 2019

DOI: $10.1039 / c 8 r a 06655 h$

rsc.li/rsc-advances

\section{Film based on magnesium impregnated biochar/ cellulose acetate for phosphorus adsorption from aqueous solution $\uparrow$}

Marina de Carvalho Eufrásio Pinto, ${ }^{a}$ Demetrius David da Silva, ${ }^{a}$ Ana Luiza Amorim Gomes, ${ }^{\text {b }}$ Victor dos Santos Azevedo Leite, ${ }^{\mathrm{b}}$ Allan Robledo Fialho e Moraes, ${ }^{\mathrm{c}}$

Roberto Ferreira de Novais, ${ }^{c}$ Jairo Tronto (DD ${ }^{\mathrm{b}}$ and Frederico Garcia Pinto (D) ${ }^{\star b}$

Phosphorus (P) is a nutrient necessary for agricultural production and a potential originator for eutrophication in water bodies, resulting in qualitative changes; it may also affect the aquatic ecosystem and human health. In addition, as a finite resource, the importance of studying strategies to remove it from water is evident, thus making possible its recycling. Many studies have used powdered materials, including biochars, for $\mathrm{P}$ water decontamination; however, the difficulty of separating and collecting these materials from water after adsorption may be difficult. Therefore, using hybrid materials in which the fine particles (powder) are impregnated into larger, solid particles by means of a polymeric host can facilitate collection and reuse after $\mathrm{P}$ adsorption. In this context, this study aimed the synthesis and characterization of a new hybrid film formed by the biopolymer cellulose acetate (CA) and biochar (FAC$B$ ) for $\mathrm{P}$ adsorption in aqueous solution. We obtained biochar from the pyrolysis of carrot residue (Daucus carota L.) and doped it with magnesium. As a biodegradable polymer and the most abundant natural polysaccharide in the environment, using CA as a biochar support material is an environmentally friendly alternative. We prepared the CA film with the casting method, and the biochar was inserted into the filmogenic solution in the same amount as the CA. The film was characterized by $\mathrm{X}$-ray diffraction (XRD), thermogravimetric analysis (TGA), differential scanning calorimetry (DSC), molecular absorption spectroscopy in the infrared region with an attenuated total reflectance (FTIR/ATR) accessory, and X-ray Photoelectron Spectroscopy (XPS). We evaluated the thickness, weight, density, $\mathrm{H}_{2} \mathrm{O}$ uptake and $\mathrm{H}_{2} \mathrm{O}$ solubility of the produced FAC-B. The maximum adsorption capacity of $\mathrm{P}$ by FAC-B was $21.57 \mathrm{mg} \mathrm{g}^{-1}$, in agreement with the Langmuir isotherm model. The adsorption value suggests that the film has the potential to be used as an efficient $\mathrm{P}$ adsorbent in water.

\section{Introduction}

Biochars are materials produced by thermal degradation of biomass under limited $\mathrm{O}_{2}$ (pyrolysis) conditions, ${ }^{1}$ which have been widely applied as adsorbents of phosphorus (P) in aqueous solution. ${ }^{2,3}$ Increasing phosphorus concentration in water bodies can cause eutrophication, leading to changes such as in $\mathrm{pH}$, dissolved oxygen and water transparency, which may affect the aquatic ecosystem and human health. ${ }^{4}$

${ }^{a}$ Federal University of Viçosa, Department of Agricultural Engineering, Campus Universitário, Viçosa, MG, CEP 36570-000, Brazil

${ }^{b}$ Federal University of Viçosa, Institute of Exact Science, Campus de Rio Paranaiba, Rodovia BR $354 \mathrm{~km}$ 310, Rio Paranaíba, MG, CEP 38810-000, Brazil. E-mail: fredericogarcia.ufv@gmail.com

'Federal University of Viçosa, Institute of Agrarian Science, Campus de Rio Paranaíba, Rodovia BR $354 \mathrm{~km}$ 310, Rio Paranaíba, MG, CEP 38810-000, Brazil

$\dagger$ Electronic supplementary information (ESI) available. See DOI: $10.1039 / \mathrm{c} 8 \mathrm{ra} 06655 \mathrm{~h}$
$\mathrm{P}$ is a finite and essential element for plant development and, with the continuous increase of the world population, greater quantities of this element are necessary to guarantee food production. ${ }^{5,6}$ Moreover, in tropical soils, much of the $\mathrm{P}$ applied is not available to the plants, being occluded in the soil retained by minerals such as gibbsite and goethite, causing large quantities of phosphate fertilizers to be applied to achieve high crop yields. ${ }^{7}$ Thus, strongly fixed in the soil, $\mathrm{P}$ can be dragged to bodies of water by surface runoff and erosion, causing contamination. $^{\mathbf{8 - 1 0}}$

The adsorption of $\mathrm{P}$ in a biochar without any additional treatment is unlikely due to the presence of carboxylic and phenolic groups that prevent the adsorption of anions such as those from $\mathrm{P.}^{\mathbf{1 1 - 1 3}}$

Different techniques for the chemical modification of the biochar have been used for the insertion of cations in the biochars, allowing to reach high rates of $\mathrm{P}$ removal due to the appearance of a cation bridge between the biochar and the 
anion to be adsorbed. ${ }^{13-19}$ In this work, was performed the doping of the biochar using magnesium.

Recent studies have shown that magnesium-modified (Mg) biochars are effective at removing $\mathrm{P}$ in aqueous solution..$^{12,20-24}$ However, even with a great capacity for $\mathrm{P}$ removal in aqueous solution, the difficulty of collecting and reusing powdered materials after the adsorption process can make the use of the biochars as adsorbent materials less attractive. ${ }^{25}$ According to Shepherd et al. ${ }^{26}$ it is of great importance that the captured $\mathrm{P}$ is subsequently recycled, rather than becoming a waste product of the process. An effective alternative to solving this problem is the synthesis of hybrid composites by impregnating or coating fine particles into larger sized, solid particles ${ }^{27}$ using a polymeric host. ${ }^{28}$

Biodegradable biopolymers are an environmentally friendly alternative, since they come from renewable and biodegradable sources. Composites using biodegradable biopolymers as matrices to support different adsorbents materials have been studied for contaminant removal in aqueous solution. Among them are spherical composites using cellulose matrices, ${ }^{29,30}$ calcium alginate, ${ }^{31,32}$ chitosan, ${ }^{33,34}$ and still, fibrous composites of chitosan (Razzaz et al., 2016)..$^{35}$

Cellulose acetate (CA) is a biodegradable thermoplastic polymer derived from cellulose esterification, which is the most abundant natural polysaccharide in the environment. ${ }^{36}$ Depending on its degree of substitution (GS), CA is used in the manufacture of different commercial products, such as fabrics, plastics, photographic films and cigarette filters. ${ }^{37}$

In a large research carried out in the specialized literature, there were no reports on biochar immobilization in biodegradable CA films. Thus, this work aimed at synthesizing a hybrid film of cellulose acetate and biochar from carrot residue pretreated with magnesium, its characterization and, furthermore, adsorption studies of $\mathrm{P}$ in this new material.

\section{Experimental}

Milli-Q ${ }^{\circledR}$ deionized $\mathrm{H}_{2} \mathrm{O}$ was used in this study to prepare all the solutions, and also to wash the carrot to obtain the biochar. All used chemical reagents have analytical purity. The reagents were $\mathrm{KH}_{2} \mathrm{PO}_{4}$ Dinâmica $99 \%, \mathrm{MgCl}_{2} \cdot 6 \mathrm{H}_{2} \mathrm{O}$ Vetec $99 \%, \mathrm{NaOH}$ neon $98.4 \%$, $\mathrm{HCl}$ Moderna 37\%, acetone P.A., chromate and cellulose acetate (AC), Rhodia. $\mathrm{N}_{2}$ gas used in biochar synthesis was from White Martins at $\mathbf{9 9 . 9 9 \%}$ purity.

\subsection{Biochar from pre-treated carrot in magnesium solution}

For biochar synthesis, was used carrot residue (Daucus carota L.). The carrot is an interesting raw material for the production of biochar as it is one of the most efficient crops in the accumulation of biomass. ${ }^{38}$ In Brazil, high yields of carrot production have been achieved in crops (above $80 \mathrm{t} \mathrm{ha}^{-1}$ ). ${ }^{39}$ However, according to reports from producers 20 to $40 \%$ of supplied carrot is discarded for different reasons, generating large quantities of organic waste. Thus, it is interesting to study a reuse of this waste biomass. The carrot sample was collected in a crop in the region of Alto Paranaíba, state of Minas Gerais,
Brazil. The carrot sample was washed, processed and oven dried at $80^{\circ} \mathrm{C}$ for $72 \mathrm{~h}$. The dried biomass was then ground in a knife mill and sieved to a particle size of less than 30 mesh. This ground material was immersed in a solution containing $120 \mathrm{~g}$ $\mathrm{MgCl}_{2} \cdot 6 \mathrm{H}_{2} \mathrm{O}$ dissolved in $360 \mathrm{~mL}$ deionized $\mathrm{H}_{2} \mathrm{O}$, with mass ratio of carrot to solution volume of $1: 10$ and kept under magnetic stirring for $2 \mathrm{~h}$. Subsequently, the biomass treated in magnesium solution was dried in an oven at $80^{\circ} \mathrm{C}$ for $72 \mathrm{~h}$ and ground them in the knife mill again. The powder was then pyrolyzed at $400{ }^{\circ} \mathrm{C}$ for $2 \mathrm{~h}$ in a tubular oven under $\mathrm{N}_{2}$ atmosphere. After this procedure, the biochars were macerated and sieved through a 100 mesh.

\subsection{Biodegradable cellulose acetate film}

The cellulose acetate film was prepared with the casting method. ${ }^{40}$ In order to obtain the filmogenic solution, we solubilized CA in acetone at the ratio of $1: 10(\mathrm{~m} / \mathrm{v})$, resting for $24 \mathrm{~h}$ in a completely sealed glass vial at room temperature. Then, the solution was subjected to magnetic stirring for $2 \mathrm{~h}$. The filmogenic solution was poured onto a glass plate, remaining at rest until complete solvent evaporation. The cellulose acetate film was named FAC.

\subsection{Biodegradable film of cellulose acetate and biochar}

CA was solubilized in acetone as described previously. After the resting period of $24 \mathrm{~h}$, the solution was subjected to magnetic stirring and the biochar was slowly added with a ratio of CA to biochar of $1: 1\left(\mathrm{~m} \mathrm{~m}^{-1}\right)$. After $2 \mathrm{~h}$ of stirring, the resulting filmogenic solution was applied onto the glass plate for solvent evaporation, resulting in cellulose acetate and biochar (FAC-B) film.

All materials synthesized in this study were stored in a vacuum desiccator with silica gel until the time of its use.

Images of the filmogenic solution during FAC-B preparation and of this same film ready to be used in the adsorption tests are presented as ESI, corresponding to Fig. S1 and S2, $\dagger$ respectively.

\subsection{Characterization of materials}

2.4.1. X-rays diffraction (XRD). XRD analysis of biochar samples, FAC, FAC-B, and the cellulose acetate film with biochar after $\mathrm{P}$ adsorption (FAC-B-P) occurred using a machinery Shimadzu XRD-6000 with a graphite crystal as a monochromator to select the $\mathrm{Cu}-\mathrm{K} \alpha 1$ radiation with $\lambda=1.5406 \AA$ and a step of $0.02^{\circ} \mathrm{s}^{-1}$, with a $2 \theta$ scanning angle between 4 and $70^{\circ}$.

2.4.2. Thermogravimetric analysis (TGA). Thermogravimetric analysis took place on equipment DTG $60 \mathrm{H}$ (Shimadzu Co., Japan). We heated about $3.0 \mathrm{mg}$ biochar, FAC and FAC-B from $25{ }^{\circ} \mathrm{C}$ to $700{ }^{\circ} \mathrm{C}$ at a heating rate of $10{ }^{\circ} \mathrm{C} \min ^{-1}$ under $\mathrm{N}_{2}$ atmosphere $\left(50 \mathrm{~mL} \mathrm{~min}^{-1}\right) .{ }^{41}$ The decomposition temperatures of the compounds were obtained from the first derivative of mass loss (\%) versus temperature (DTGA).

2.4.3. Differential scanning calorimetry (DSC). Differential scanning calorimetry analysis of FAC and FAC-B occurred by using equipment DSC 60 (Shimadzu Co., Japan). We submitted $7.0 \mathrm{mg}$ samples to the following conditions: heating from $30{ }^{\circ} \mathrm{C}$ 
to $255{ }^{\circ} \mathrm{C}$ at a heating rate of $10{ }^{\circ} \mathrm{C} \mathrm{min}^{-1}$. The $\mathrm{N}_{2}$ flow was 50 $\mathrm{mL} \min ^{-1}$.

2.4.4. Molecular absorption spectroscopy in the infrared region with attenuated total reflectance (FTIR/ATR). The FTIR/ ATR analysis was for biochar, FAC, and FAC-B on the Spectrometer Jasco, model FT/IR-4100. The spectra were obtained with a resolution of $4 \mathrm{~cm}^{-1}$ in a wavelength range from 4000 to $400 \mathrm{~cm}^{-1}$ with 256 scannings for each spectrum.

2.4.5. X-ray photoelectron spectroscopy (XPS). XPS measurements were performed in a UNI-SPECS UHV spectrometer. The spectra were obtained using a magnesium source with $\mathrm{K} \alpha$ line $(E=1253.6 \mathrm{eV})$ and the energy pass through the analyzer was set to $10 \mathrm{eV}$. The pressure in the analytical chamber was less than $10^{-7} \mathrm{~Pa}$. The binding energy scale was calibrated using line $4 \mathrm{f}$ of $\mathrm{Au}$. The surface composition of the material was evaluated based on the binding sites and energies of the central levels $\mathrm{C} 1 \mathrm{~s}, \mathrm{O} 1 \mathrm{~s}, \mathrm{Mg} 1 \mathrm{~s}$ and $\mathrm{P} 2 \mathrm{p}$.

2.4.6. Thickness, weight and density of films. FAC and FAC-B thicknesses were measured at 5 random points and the mean values were calculated. For this, we used a digital micrometer (produced by Mitutoyo Corporation, Japan) model ID-C112XB, with a $0.001 \mathrm{~mm}$ resolution. To obtain the film weights, the dry sample masses was divided by their areas, and calculated the film densities by the ratio of the masses of the film samples to the volumes thereof.

2.4.7. Water absorption in films. The degree of swelling of FAC and FAC-B was determined in agreement to the method of Jipa et al. slightly modified using eqn (1). ${ }^{42}$

$$
\mathrm{GI}=\frac{\left(m_{\mathrm{i}}-m_{\mathrm{s}}\right) \times 100}{m_{\mathrm{s}}}
$$

in which GI is the degree of swelling of the film (\%), $m_{\mathrm{i}}$ is the mass of the swollen film $(\mathrm{g})$ and $m_{\mathrm{s}}$ is the mass of the dry film (g).

To obtain the swollen mass, we submerged film samples measuring $7 \times 2.5 \mathrm{~cm}$ in $50 \mathrm{~mL} \mathrm{H}_{2} \mathrm{O}$ for $2 \mathrm{~h}$ at $25^{\circ} \mathrm{C}$. After this period, excess $\mathrm{H}_{2} \mathrm{O}$ from film surface was removed using an absorbent paper and the masses of the swollen samples were obtained in triplicate and the mean values were obtained for FAC and FAC-B.

2.4.8. Solubility in water $\left(\boldsymbol{S}_{\mathrm{H}_{2} \mathrm{O}}\right)$. For estimate of FAC-B solubility in $\mathrm{H}_{2} \mathrm{O}$, FAC-B samples $(7 \times 2.5 \mathrm{~cm})$ were submerged in $50 \mathrm{~mL}$ vials containing $\mathrm{H}_{2} \mathrm{O}$ (in triplicate) and kept under stirring at $25{ }^{\circ} \mathrm{C}$. After shaking for $48 \mathrm{~h}$, the film samples were dried and weighed. Eqn (2) calculated $S_{\mathrm{H}_{2} \mathrm{O}}$.

$$
S_{\mathrm{H}_{2} \mathrm{O}}=\frac{\left(m_{\mathrm{i}}-m_{\mathrm{f}}\right) \times 100}{m_{\mathrm{i}}}
$$

in which $S_{\mathrm{H}_{2} \mathrm{O}}$ is the solubility in $\mathrm{H}_{2} \mathrm{O}$ of the film (\%), $m_{\mathrm{i}}$ is the film initial mass $(\mathrm{g})$ and $m_{\mathrm{f}}$ is the film mass at the end of 48 hours of stirring in $\mathrm{H}_{2} \mathrm{O}(\mathrm{g})$.

\subsection{Experiments of adsorption of $P$ in aqueous solution}

An aqueous stock solution of $1000 \mathrm{mg} \mathrm{L}^{-1}$ of $\mathrm{P}$ was prepared by dissolving $\mathrm{KH}_{2} \mathrm{PO}_{4}$ in $\mathrm{H}_{2} \mathrm{O}$ and, thereafter, we diluted this solution at different concentrations to conduct the adsorption experiments.

$\mathrm{P}$ adsorption experiments in the films were in triplicate and the mean values reported. The molybdenum blue spectrophotometric method determined $\mathrm{P}$ concentrations in solution in a UV-vis spectrophotometer (Thermo model Evolution 300). ${ }^{43}$

Using eqn (3), the amount of adsorbed P was calculated.

$$
q_{\mathrm{e}}=\frac{\left(C_{0}-C_{\mathrm{e}}\right) \times V}{m}
$$

in which $q_{\mathrm{e}}$ is the amount of $\mathrm{P}$ adsorbed $\left(\mathrm{mg} \mathrm{g}^{-1}\right), C_{0}$ is the initial concentration $\left(\mathrm{mg} \mathrm{L}^{-1}\right), C_{\mathrm{e}}$ is the balance concentration $\left(\mathrm{mg} \mathrm{L}^{-1}\right), V$ is the solvent volume (L), and $m$ is the mass of adsorbent sample (g).

2.5.1. Kinetics of adsorption. In the kinetics of adsorption study, FAC-B with a mass of around $2.5 \mathrm{~g}$ were kept under stirring in bottles containing $500 \mathrm{~mL} \mathrm{P}$ solution $\left(50 \mathrm{mg} \mathrm{L}^{-1}\right)$ in a thermostated bath at $25{ }^{\circ} \mathrm{C}$. At different time intervals, ranging from $0.5 \mathrm{~h}$ to $96 \mathrm{~h}$, samples were withdrawn from the suspensions and $\mathrm{P}$ concentrations were determined. We used the kinetics models of pseudo-first order (eqn (4)) and pseudosecond order (eqn (5)) to simulate experimental kinetics.

$$
\begin{aligned}
& \frac{\mathrm{d} q_{t}}{\mathrm{~d} t}=k_{1}\left(q_{\mathrm{e}}-q_{t}\right) \\
& \frac{\mathrm{d} q_{t}}{\mathrm{~d} t}=k_{2}\left(q_{\mathrm{e}}-q_{t}\right)^{2}
\end{aligned}
$$

in which, $k_{1}$ and $k_{2}$ are respectively the adsorption rate constants of pseudo-first order and pseudo-second order $\left(\mathrm{h}^{-1}\right)$, $q_{\mathrm{e}}$ and $q_{t}$ are the adsorbed amounts per gram of adsorbent at equilibrium and in time $t$ respectively $\left(\mathrm{mg} \mathrm{g}^{-1}\right)$.

2.5.2. Isotherm of adsorption. To construct the adsorption isotherms, films of size $7.0 \times 2.5 \mathrm{~cm}$ (around $250 \mathrm{mg}$ ) of FAC-B were immersed in $50 \mathrm{~mL}$ solutions of $\mathrm{P}$, at different concentrations, ranging from 2.5 to $200 \mathrm{mg} \mathrm{L}^{-1}$. The suspensions remained under stirring in a thermostated bath at $25{ }^{\circ} \mathrm{C}$ for $48 \mathrm{~h}$. The Langmuir (eqn (6)) and Freundlich (eqn (7)) isotherms models were used to describe $\mathrm{P}$ adsorption in FAC-B.

$$
\begin{gathered}
q_{\mathrm{e}}=\frac{q_{\mathrm{m}} K_{\mathrm{L}} C_{\mathrm{e}}}{1+K_{\mathrm{L}} C_{\mathrm{e}}} \\
q_{\mathrm{e}}=K_{\mathrm{F}} C_{\mathrm{e}^{n}}^{\frac{1}{n}}
\end{gathered}
$$

in which, $q_{\mathrm{e}}$ is the adsorbed amount of solute at equilibrium per gram of adsorbent $\left(\mathrm{mg} \mathrm{g}^{-1}\right), C_{\mathrm{e}}$ is the concentration of solute in equilibrium $\left(\mathrm{mg} \mathrm{L}^{-1}\right), q_{\mathrm{m}}\left(\mathrm{mg}^{-1}\right)$ is the maximum adsorption capacity, $K_{\mathrm{L}}$ and $K_{\mathrm{F}}$ are respectively the Langmuir and Freundlich constants and $n$ is a constant that reports adsorption intensity.

2.5.3. Influence of $\mathbf{p H}$ value on $\mathbf{P}$ adsorption. To evaluate the $\mathrm{pH}$ effect of the initial solution on $\mathrm{P}$ adsorption, FAC-B of 7.0 $\times 2.5 \mathrm{~cm}$ dimensions (approximately $250 \mathrm{mg}$ ) were added to $50 \mathrm{~mL}$ solutions of $\mathrm{P}$ with a concentration of $85 \mathrm{mg} \mathrm{L}^{-1}$ at different $\mathrm{pH}$ values $(2,4,6,8$ and 10) and kept under stirring at $25{ }^{\circ} \mathrm{C}$ for $48 \mathrm{~h}$. To adjust the $\mathrm{pH}$ values, were used $\mathrm{HCl}$ and $\mathrm{NaOH} 0.1 \mathrm{~mol} \mathrm{~L}^{-1}$ solutions. 


\section{Results and discussion}

\subsection{Characterization of materials}

3.1.1. X-rays diffraction (XRD). Fig. 1 shows X-ray diffractograms for biochar from carrot residues and pretreated with $\mathrm{Mg}$, FAC, FAC-B and FAC-B-P.

For FAC (Fig. 1a), the diffractogram showed two extremely broad peaks and low intensity $2 \theta$ between 8 and $25^{\circ}$. This diffraction pattern refers to the onset of a disorder in the material due to cellulose acetylation (\#). The biochar XRD (Fig. 1b) showed diffraction peaks related to $\mathrm{MgCl}_{2}(\boldsymbol{\square})$ from the doping method of biochar and peaks related to the $\mathrm{MgO}(\mathrm{O})$ formation in the material. For FAC-B, the diffractogram shows characteristics of a material containing the mixture of polymer and biochar (Fig. 1c). The diffractogram presents the profile of peaks referring to the biochar and low intensity peaks related to CA presence. In relation to FAC-B after P adsorption (Fig. 1d), several peaks referring to biochar disappeared. XPS analyzes were performed in the FAC-B demonstrating the formation of the $\mathrm{Mg}\left(\mathrm{H}_{2} \mathrm{PO}_{4}\right)_{2}$ after the adsorption of $\mathrm{P}$ in the film. In addition, the concentration of magnesium in the FAC-B after the adsorption of $\mathrm{P}$ was determined and it decreased by $25 \%$. Thus, most of the magnesium still remained impregnated in the polymer matrix after adsorption of $\mathrm{P}$. The decrease of peak intensities displayed in Fig. 1d is probably due to the formation of species with low crystallinity on the surface of the material and the leaching of part of the magnesium during the adsorption process. The peaks relative to $\mathrm{CA}$ remained unchanged showing material stability after $\mathrm{P}$ adsorption.

3.1.2. Thermogravimetric analysis (TGA). Fig. 2 shows the TGA curves for FAC, biochar and FAC-B.

According to the TGA thermogram obtained for the FAC, initially, there is a slight mass loss of $3 \%$ up to $200{ }^{\circ} \mathrm{C}$, corresponding to the loss of volatile compounds and $\mathrm{H}_{2} \mathrm{O}$ bound to the hydrophilic $(\mathrm{OH})$ groups of the CA chains and, subsequently, to CA deacetylation. ${ }^{\mathbf{4 4 - 4 8}}$

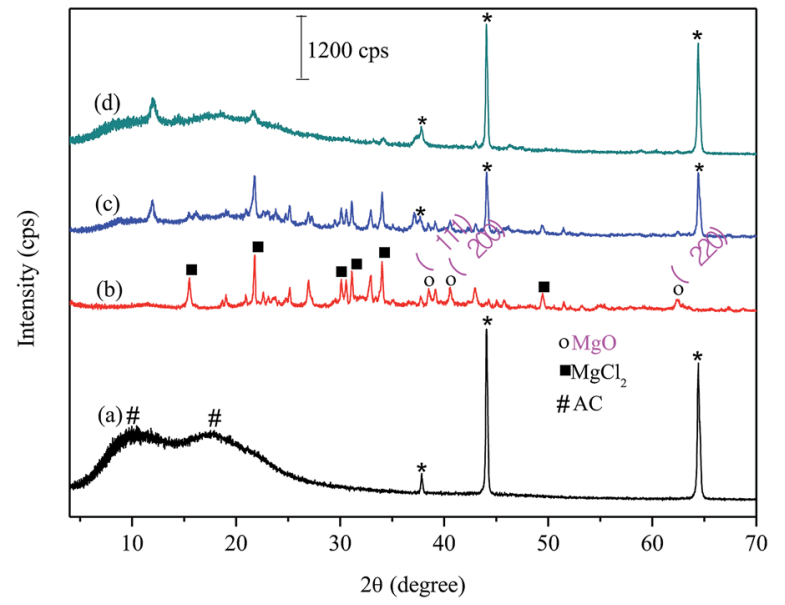

Fig. 1 X-ray diffractograms for (a) cellulose acetate film (FAC); (b) biochar; (c) cellulose acetate/biochar film (FAC-B); (d) cellulose acetate/biochar film after $\mathrm{P}$ adsorption (FAC-B-P). * = peaks referring to the aluminium sample holder.

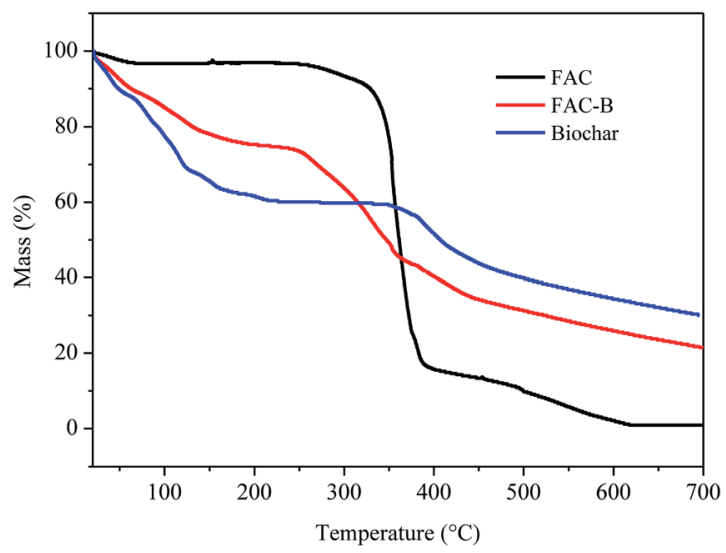

Fig. 2 Thermogravimetric analysis (TGA) for cellulose acetate film (FAC), cellulose acetate/biochar film (FAC-B) and biochar.

There were two more stages of thermal decomposition for this material; the first step was between 300 and $400{ }^{\circ} \mathrm{C}$, with mass loss of $79 \%$, and the second was between 400 and $600{ }^{\circ} \mathrm{C}$, with mass loss of $14 \%$. The first stage $\left(300-400{ }^{\circ} \mathrm{C}\right)$ corresponds to the main thermal decomposition event and can be attributed to CA chain degradation due to the breakdown of glycosidic bonds followed by the primary decomposition in volatile and dehydrated compounds. The final stage of mass loss (400-600 ${ }^{\circ} \mathrm{C}$ ) is attributed to sample carbonization, resulting in complete degradation and decomposition of the film. ${ }^{\mathbf{4 4 - 4 8}}$

For biochar, were observed two stages of mass loss. The first stage was between 30 and $230{ }^{\circ} \mathrm{C}$, with mass loss of $40 \%$ which, according to Zhang et al. ${ }^{20}$ can be attributed to the loss of $\mathrm{H}_{2} \mathrm{O}$ adsorbed on the material and by the degradation of lignocellulosic fractions did not decompose during the pyrolysis process at $400{ }^{\circ} \mathrm{C}$. The second stage of biochar thermal decomposition, starting at $380{ }^{\circ} \mathrm{C}$, can be attributed to the release of minerals and salts from the material as also observed by Cimò et al. ${ }^{49}$ The final mass of this material corresponded to approximately $35 \%$ of its initial mass, indicating its high mineral residue content.

From the thermogram of FAC-B, we observed three stages of thermal decomposition between the ranges $30-200{ }^{\circ} \mathrm{C}, 215-$ $380{ }^{\circ} \mathrm{C}$, and above $380{ }^{\circ} \mathrm{C}$. This thermogram showed an intermediate profile in relation to the thermograms of FAC and biochar, that is, for each of the temperature ranges of the cited thermal events, their mass variation occurred approximately as an average of the other two thermograms, because the film is formed by $50 \%$ by weight of each component. The first step, with mass loss of approximately $20 \%$, can be attributed mainly to the release of $\mathrm{H}_{2} \mathrm{O}$ by the material by the presence of biochar, with the FAC mass in this temperature range practically constant. The second decomposition step is probably due to degradation of CA chain, with the biochar mass remaining almost unchanged. FAC mass loss in this stage was $80 \%$. The third and final step can be attributed to polymer carbonization with total film degradation and part of biochar. FAC-B showed thermal stability lower than the FAC with maximum mass loss of CA at 335 and $360{ }^{\circ} \mathrm{C}$, respectively. The onset temperatures 
for this event also followed the same behaviour for the two materials, $314{ }^{\circ} \mathrm{C}$ for FAC and $230{ }^{\circ} \mathrm{C}$ for FAC-B. This phenomenon, in its turn, means that the FAC functioned merely as a physical support for the biochar which is quite positive since the active sites of biochar remains available for phosphorus adsorption from aqueous solution.

3.1.3. Differential scanning calorimetry (DSC). Fig. 3 shows the DSC thermograms of FAC and FAC-B.

The DSC thermograms obtained for FAC and FAC-B showed similar profiles; the main difference was the initial temperature, peak and final melting temperature, as well as the enthalpy involved in this process. The initial, peak and final temperatures for FAC were 210,211 and $216^{\circ} \mathrm{C}$, respectively, whereas for FAC-B were 190, 192 and $204{ }^{\circ} \mathrm{C}$, respectively. FAC-B melting occurred at a temperature lower than FAC melting. This fact may be attributed to a weakening as well as a smaller number of interactions between the CA chains due to the presence of the biochar in the film. The melting enthalpy for FAC was $660 \mathrm{~kJ} \mathrm{~g}^{-1}$ while for FAC-B it was $3600 \mathrm{~kJ} \mathrm{~g}^{-1}$. The higher energy involved during the FAC-B melting process may be due to water volatilization, since TGA showed large mass loss in this temperature range.

3.1.4. Molecular absorption spectroscopy in the infrared region with attenuated total reflectance (FTIR/ATR). Fig. 4 shows the FTIR/ATR spectra for FAC, biochar and FAC-B.

The FTIR/ATR spectrum for FAC (Fig. 4a) shows a band at $1741 \mathrm{~cm}^{-1}$, typical of the formation of CA chains, attributed to the vibrational stretching of carbonyl $(\mathrm{C}=\mathrm{O})$ groups of esters present in the CA molecule. There were also other characteristic bands for this material, among them two, one stand out in $1037 \mathrm{~cm}^{-1}$ related to vibrational modes of the $\mathrm{C}-\mathrm{O}-\mathrm{C}$ binding and another in $1225 \mathrm{~cm}^{-1}$ by stretching the $\mathrm{C}-\mathrm{O}$ binding, both present in the CA molecule. A small band was observed at $1371 \mathrm{~cm}^{-1}$ which may associate with the stretching of the $\mathrm{C}-\mathrm{H}$ binding of $-\mathrm{CH}_{3}$ groups present on acetate radicals. For the biochar (Fig. 4b), a band centered at $3400 \mathrm{~cm}^{-1}$ appeared, attributed to the stretching of $\mathrm{O}-\mathrm{H}$ bidings of hydroxyl groups

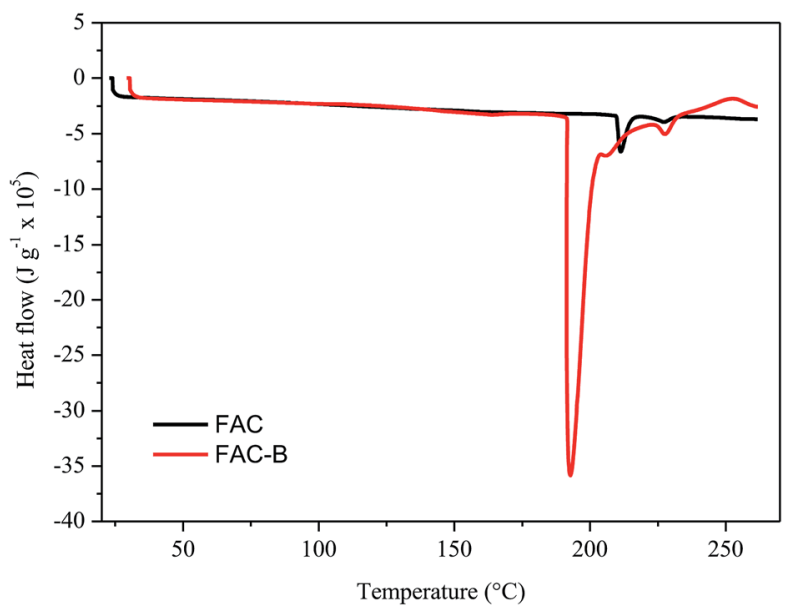

Fig. 3 Differential scanning calorimetry (DSC) for cellulose acetate film (FAC) and cellulose acetate/biochar film (FAC-B).

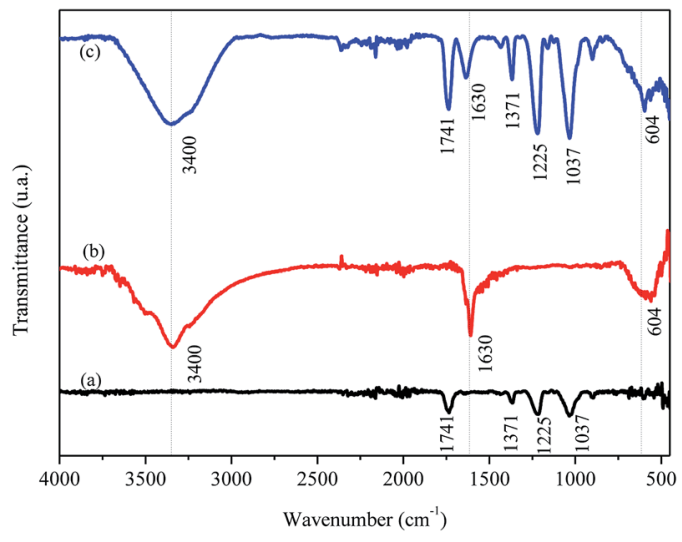

Fig. 4 Molecular absorption spectroscopy in the infrared region with attenuated total reflectance (FTIR/ATR) for the (a) cellulose acetate film (FAC), (b) biochar and (c) cellulose acetate/biochar film (FAC-B).

and molecules of $\mathrm{H}_{2} \mathrm{O}$ in this material. There were another two bands in the biochar spectrum, one in $1630 \mathrm{~cm}^{-1}$ characteristic of carbonaceous materials related to the stretching of $\mathrm{C}=\mathrm{C}$ bindings of aromatics ${ }^{50}$ or by stretching the $\mathrm{C}=\mathrm{O}$ binding of carboxylates and ketones ${ }^{14}$ and the other in $604 \mathrm{~cm}^{-1}$ attributed to $\mathrm{Mg}-\mathrm{O}$ vibrations in the biochar. ${ }^{51}$ The same bands observed in FAC and in biochar appeared in FAC-B, which was expected because the film was formed by $50 \%$ mass of both materials.

3.1.5. X-ray photoelectron spectroscopy (XPS). XPS analysis of the film was performed after the adsorption of P. For the adsorption of $\mathrm{P}$ on the surface of the film were placed $2.5 \mathrm{~g}$ of film in $500 \mathrm{~mL}$ of solution of $\mathrm{P}\left(50 \mathrm{mg} \mathrm{L}^{-1}\right)$ for a period of $36 \mathrm{~h}$. Fig. 5 shows the XPS spectrum for element $\mathrm{P}$.

It can be seen from Fig. 5 that $\mathrm{Mg}\left(\mathrm{H}_{2} \mathrm{PO}_{4}\right)_{2}$ was formed on the surface of the film after adsorption of $\mathrm{P}$, probably due to the reaction between the oxyanions of $\mathrm{P}$ and the $\mathrm{MgO}$ present in the material. In addition, it was possible to observe the presence of oxides of $\mathrm{P}$ on the surface of the material probably connected by electrostatic attraction on the surface of the film. The XPS spectra for $\mathrm{C}, \mathrm{O}$, and $\mathrm{Mg}$ can be found in the supplemental material (Fig. S3†). Similar result was obtained by Yao et al. (2013) using engineered biochar prepared from Mg-enriched tomato tissues.

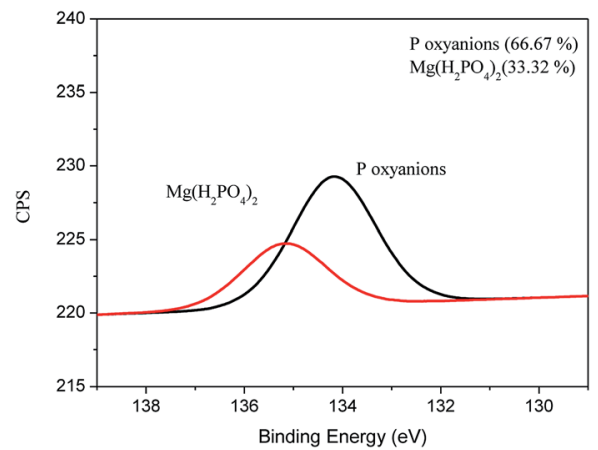

Fig. 5 Phosphorus XPS spectrum of FAC-B after phosphorus adsorption. 
Table 1 Comparison of adsorption capacity of several polymeric adsorbents for $\mathrm{P}$ removal

\begin{tabular}{lcl}
\hline & $\begin{array}{l}\text { Adsorption } \\
\text { capacity } \\
\left(\mathrm{mg} \mathrm{g}^{-1}\right)\end{array}$ & References \\
Adsorbent & 13.94 & 55 \\
\hline $\begin{array}{l}\text { Gel derived from orange residue } \\
\text { treated with } \mathrm{Ca}(\mathrm{OH})_{2}\end{array}$ & \\
$\begin{array}{l}\text { Wood fiber } \\
\text { Coconut fiber doped with zinc }\end{array}$ & 4.30 & 56 \\
Collagen fiber loaded with zirconium & 28.47 & 57 \\
Polyurethane foam & 11.78 & 58 \\
Refined aspen wood fiber & 4.3 & 60 \\
Fe $\mathrm{O}_{4} /$ polysulfone ultrafiltration membrane & 0.684 & 61 \\
Anion-functionalized nanoporous polymer & 4.92 & 62 \\
Hybrid film of cellulose acetate and biochar & 21.57 & This work \\
made from carrot residue & &
\end{tabular}

3.1.6. Thickness, weight, density, water absorption and water solubility of FAC and FAC-B films. Table S1† shows the results obtained for thickness, weight, density, degree of swelling and water solubility of FAC and FAC-B.

Table S1 $\uparrow$ shows the FAC thickness modified after the incorporation of biochar in the film. The FAC-B hybrid material had higher film thickness. These variations in thickness may also influence other properties of these materials, such as $\mathrm{H}_{2} \mathrm{O}$ uptake. ${ }^{52}$

From the data shown in Table $\mathrm{S} 1, \uparrow$ there was a large difference in GI (water absorption) between FAC and FAC-B. This $\mathrm{H}_{2} \mathrm{O}$ uptake depends on the hydrophilicity and chemical nature of the materials, ${ }^{46}$ also on its morphological structure. ${ }^{53}$ Thus, a higher GI occurred for FAC-B compared to FAC, which can be attributed to the greater porosity and thickness of FAC-B, as well as to hydrophilic character of the biochar in the hybrid film.

As biodegradable films are originally used for food packaging or encapsulation, water solubility is a desirable feature. ${ }^{42}$ However, in other applications, as evaluated in this study, water insolubility improves material integrity and water resistance. ${ }^{\mathbf{4 2 , 5 4}}$ Table 1 shows that, after $48 \mathrm{~h}$ of FAC-B contact with water, $33 \%$ of the film mass was solubilized in water.

\section{2. $P$ adsorption}

3.2.1. Kinetics of adsorption. Fig. 6 shows that after $24 \mathrm{~h}$ of contact of FAC-B film with solution containing P, $74.4 \%$ of the $q_{\mathrm{e}}$ value was reached; balance occurred in approximately $48 \mathrm{~h}$. According to Yao et al., ${ }^{12}$ the slow kinetics suggests that precipitation has no important role in $\mathrm{P}$ removal by biochar.

The kinetics model of pseudo-first order had the best fit for the experimental data with coefficient of determination $\left(R^{2}\right)$ equal to 0.98 (Table $\mathrm{S} 2 \dagger$ ).

3.2.2. Isotherm of adsorption. Fig. 7 shows the experimental data of isotherm of $\mathrm{P}$ adsorption in FAC-B, as well as the adjustment to the Langmuir and Freundlich models. The Langmuir model was better fitted to the experimental data, with $R^{2}=0.97$ (Table S3†). Thus, $\mathrm{P}$ adsorption in FAC-B probably occurs as monolayer on a homogeneous surface. $\mathrm{P}$ maximum adsorption capacity obtained by the Langmuir equation was $21.57 \mathrm{mg} \mathrm{g}^{-1}$.

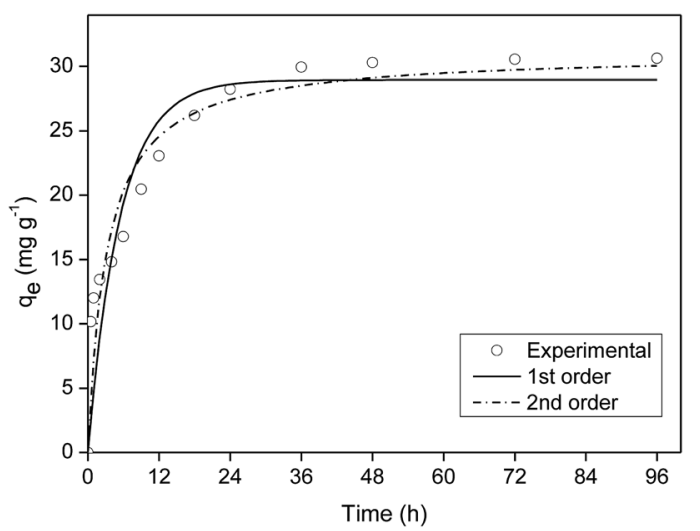

Fig. 6 Kinetics of phosphorus adsorption onto cellulose acetate/ biochar film (FAC-B).

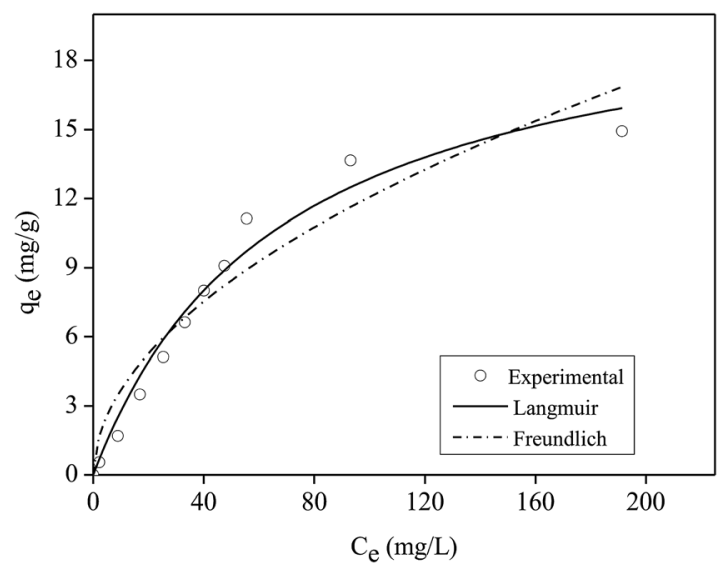

Fig. 7 Isotherm of phosphorus adsorption onto cellulose acetate/ biochar film (FAC-B).

Table 1 shows the maximum adsorption capacity values of $P$ in aqueous solution obtained by the Langmuir model in other studies that used films or other polymeric materials.

According to Table 1, the film shown in this work had high efficiency when compared to other polymeric materials presented in the literature that were applied for $\mathrm{P}$ adsorption in aqueous solution.

3.2.3. $\mathbf{p H}$ influence. The effect of varying the $\mathrm{pH}$ value of the medium on $\mathrm{P}$ adsorption by FAC-B has been studied and Fig. 8 shows the results.

Fig. 8 shows that better $\mathrm{P}$ adsorption results by FAC-B occurred at basic $\mathrm{pH}$ values. Despite the existence of $\mathrm{OH}^{-}$ anions in the medium at basic $\mathrm{pH}$, the competition between these anions and the oxyanions of $\mathrm{P}\left(\mathrm{HPO}_{4}{ }^{2-} ; \mathrm{PO}_{4}{ }^{3-}\right)$ by the adsorptive sites of the film was not sufficient to overcome the advantage of having $\mathrm{P}$ oxyanions in the more deprotonated forms at these $\mathrm{pH}$ values to bind to the film, which has a positive surface by the presence of biochar doped with magnesium. At $\mathrm{pH}$ values $=2,4$ and 6 , even though there are no competing anions in the medium, $\mathrm{P}$ species are in the most protonated forms $\left(\mathrm{H}_{3} \mathrm{PO}_{4}, \mathrm{H}_{2} \mathrm{PO}_{4}{ }^{-}\right)$, which diminished the interaction of these species with the film surface. 


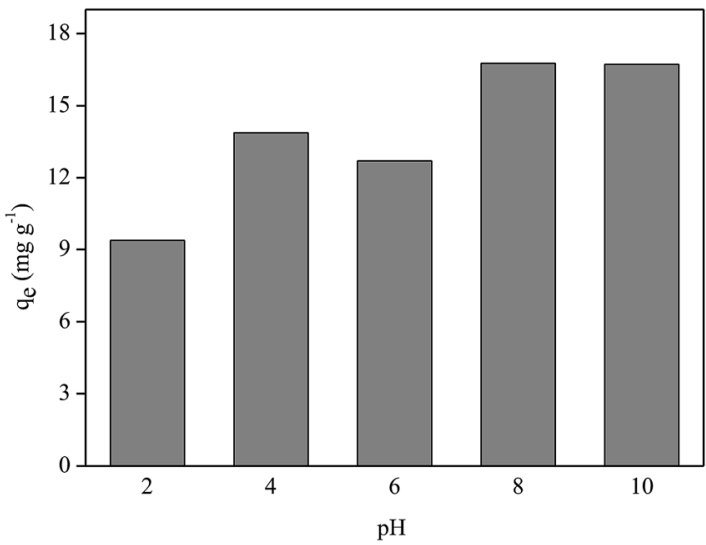

Fig. 8 Effect of pH on phosphorus adsorption onto cellulose acetate/ biochar film (FAC-B).

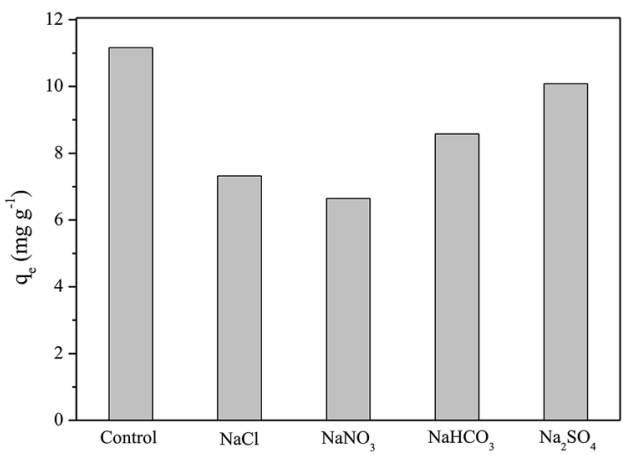

Fig. 9 Effect of coexisting anions on phosphorus adsorption onto cellulose acetate/biochar film (FAC-B).

3.2.4. Co-exist anions influence. It was observed from Fig. 9 that the adsorption capacity of $\mathrm{P}$ decreases when coexisting ions are present in solution, however, the film still exhibits good performance and affinity for $\mathrm{P}$ even with the other anions in solution.

\section{Conclusions}

The cellulose acetate and biochar hybrid film made from carrot residue pretreated with magnesium (FAC-B) showed high efficiency when compared to other polymeric materials from the literature, applied to $\mathrm{P}$ adsorption in aqueous solution.

$\mathrm{P}$ maximum adsorption capacity by FAC-B was $21.57 \mathrm{mg} \mathrm{g}^{-1}$, according to the Langmuir isotherm model and kinetics of adsorption was the pseudo-first order.

The influence study of $\mathrm{pH}$ value of the medium on $\mathrm{P}$ adsorption by FAC-B showed that better results are for $\mathrm{pH}$ values 8 and 10 .

The developed hybrid film is easy to use in adsorption studies, with advantages in relation to adsorbent materials in the form of powder, such as the non-agglomeration of adsorbent particles and their ease of removal from the medium for possible adsorbent recycling, with great potential for environmental applications.

\section{Conflicts of interest}

There are no conflicts to declare.

\section{Acknowledgements}

Marina de Carvalho Eufrásio Pinto thanks the Coordenação de Aperfeiçoamento de Pessoal de Nível Superior (CAPES) for the PhD scholarship. Victor dos Santos Azevedo Leite also thanked CAPES for the Masters scholarship. We thank the Federal University of Viçosa for the infrastructure, and the Photoelectron Spectroscopy Laboratory (LEFE) for the XPS analyzes.

\section{References}

1 J. Lehmann, Front. Ecol. Environ., 2017, 5, 381-387.

2 Z. Zeng, S. Zhang, T. Li, F. Zhao, Z. He, H. Zhao, X. Yang, H. Wang, J. Zhao and M. T. Rafiq, Biomed. Biotechnol., 2013, 14, 1152-1161.

3 K. W. Jung, K. Kim, T. U. Jeong and K. H. Ahn, Bioresour. Technol., 2016b, 200, 1024-1028.

4 C. P. O. Aguiar, J. R. P. Peleja, K. N. S. Sousa, Y. G. F. Goch and A. S. Guimarães, Revista Brasileira de Recursos Hídricos, 2015, 20, 1093-1102.

5 K. Ashley, D. Cordell and D. Mavinic, Chemosphere, 2011, 84, 737-746.

6 D. Cordell, A. Rosemarin, J. J. Schröder and A. L. Smit, Chemosphere, 2011, 84, 747-758.

7 E. D. Roy, P. D. Richards, L. A. Martinelli, L. D. Coletta, S. R. M. Lins, F. F. Vazquez and S. Porder, Nat. Plants, 2016, 2, 16043-16049.

8 E. Luz-Basã and Y. Basã, Water Res., 2004, 38, 4222-4246.

9 C. Lin, R. Ma and J. Xiong, Sci. Total Environ., 2018, 628, 870881.

10 S. Sarvajayakesavalu, Y. Lu, P. J. A. Withers, P. S. Pavinato, G. Pan and P. Chareonsudjai, Ecosystem Health and Sustainability, 2018, 4, 48-57.

11 S. Liu, X. Tan, Y. Liu, Y. Gu, G. Zeng, X. Hu, H. Wang, L. Zhou, L. Jiang and B. Zhao, RSC Adv., 2016, 6, 5871-5880.

12 Y. Yao, B. Gao, M. Inyang, A. R. Zimmerman, X. Cao, P. Pullammanappallil and L. Yang, Bioresour. Technol., 2011, 102, 6273-6278.

13 S. V. Novais, M. D. O. Zenero, J. Tronto, R. F. Conz and C. E. P. Cerri, J. Environ. Manage., 2018a, 214, 36-44.

14 Q. Yang, X. Wang, W. Luo, J. Sun, Q. Xu, F. Chen, J. Zhao, S. Wang, F. Yao, D. Wang, X. Li and G. Zeng, Bioresour. Technol., 2018, 247, 537-544.

15 M. Zhang and B. Gao, Chem. Eng. J., 2013, 226, 286-292.

16 K. W. Jung, T. U. Jeong, M. J Hwang, K. Kim and K. H. Ahn, Bioresour. Technol., 2015, 198, 603-610.

17 J. H. Park, Y. S. Ok, S. H. Kim, J. S. Cho, J. S. Heo, R. D. Delaune and D. C. Seo, Environ. Geochem. Health, 2015, 37, 969-983.

18 Z. Wang, H. Guo, F. Shen, G. Yang, Y. Zhang, Y. Zeng, L. Wang, H. Xiao and S. Deng, Chemosphere, 2015, 119, 646-653. 
19 S. Liu, X. Tan, Y. Liu, Y. Gu, G. Zeng, X. Hu, H. Wang, L. Zhou, L. Jiang and B. Zhao, RSC Adv., 2016, 6, 5871-5880.

20 M. Zhang, B. Gao, Y. Yao, Y. Xue and M. Inyang, Chem. Eng. J., 2012, 210, 26-32.

21 Y. Yao, B. Gao, J. Chen and L. Yang, Environ. Sci. Technol., 2013, 47, 8700-8708.

22 C. Fang, T. Zhang, P. Li, R. Jiang and Y. Wang, Int. J. Environ. Res. Public Health, 2014, 11, 9217-9237.

23 K. W. Jung and K. Ahn, Bioresour. Technol., 2016, 200, 10291032.

24 S. V. Novais, M. D. O. Zenero, J. Tronto, R. F. Conz and C. E. P. Cerri, J. Environ. Manage., 2018a, 214, 36-44.

25 K. W. Jung, T. Jeong, H. Kang and K. Anh, Bioresour. Technol., 2016a, 211, 108-116.

26 J. G. Shepherd, S. P. Sohi and K. V. Heal, Water Res., 2016, 94, 155-165.

27 X. Zhao, L. Lv, B. Pan, W. Zhang, S. Zhang and Q. Zhang, Chem. Eng. J., 2011, 170, 381-394.

28 G. Lofrano, M. Carotenuto, G. Libralato, R. F. Domingos, A. Markus, L. Dini, R. K. Gautam, D. Baldantoni, M. Rossi, S. K. Sharma, M. C. Chattopadhyaya, M. Giugni and S. Meric, Water Res., 2016, 92, 22-37.

29 X. Guo and F. Chen, Environ. Sci. Technol., 2005, 39, 68086818.

30 H. Zhu, S. Jia, T. Wan, Y. Jia, H. Yang, J. Li, L. Yan and C. Zhong, Carbohydr. Polym., 2011, 86, 1558-1564.

31 A. Bée, D. Talbot, S. Abramson and V. Dupuis, J. Colloid Interface Sci., 2011, 362, 486-492.

32 K. W. Jung and K. Ahn, Bioresour. Technol., 2016, 200, 10291032.

33 S. Wu, T. Liou and F. Mi, Bioresour. Technol., 2009, 100, 4348-4353.

34 H. V. Tran, L. D. Tran and Tn. Nguyen, Mater. Sci. Eng., C, 2010, 30, 304-310.

35 A. Razzaz, S. Ghorban, L. Hosayni, M. Irani and M. Aliabadi, J. Taiwan Inst. Chem. Eng., 2016, 58, 333-343.

36 J. Puls, S. A. Wilson and D. Hölter, J. Polym. Environ., 2011, 19, 152-165.

37 R. F. Moraes, C. C. Pola, A. P. Bilck, F. Yamashita, J. Tronto, E. A. A. Medeiros and N. F. F. Soares, Mater. Sci. Eng., C, 2017, 78, 932-941.

38 L. K. Diamantopoulou, L. S. Karaoglanoglou and E. G. Koukios, Bioresour. Technol., 2011, 102, 2641-2650.

39 W. A. Marouelli, R. A. Oliveira and W. L. C. Silva, Irrigação da cultura da cenoura, in Technical Circular, EMBRAPA Hortaliças, Brasília, DF, 2007, vol. 48, pp. 1-14.

40 C. C. Pola, E. A. A. Medeiros, O. L. Pereira, V. G. L. Souza, C. G. Otoni, G. P. Camilloto and N. F. F. Soares, Food Packaging and Shelf Life, 2016, 9, 69-78.
41 P. S. Garcia, M. V. E. Grossmann, M. A. Shirai, M. M. Lazaretti, F. Yamashita, C. M. O. Muller and S. Mali, Ind. Crops Prod., 2014, 52, 305-312.

42 M. Jipa, A. Stoica-guzun and M. Stroescu, LWT-Food Sci. Technol., 2012, 47, 400-406.

43 J. M. Braga and B. V. Defelipo, Rev. Ceres, 1974, 21, 73-85.

44 Z. Q. Liu, A. M. Cunha, X.-S. Yi and C. A. Bernardo, J. Macromol. Sci., Part B: Phys., 2001, 40, 529-538.

45 D. Puglia, A. Tomassucci and J. M. Kenny, Polym. Adv. Technol., 2003, 14, 749-756.

46 V. A. Alvarez and A. Vázquez, Polym. Degrad. Stab., 2004, 84, 13-21.

47 F. J. Rodriguez, M. J. Galotto, A. Guarda and J. E. Bruna, J. Food Eng., 2012, 110, 262-268.

48 C. C. Pola, E. A. A. Medeiros, O. L. Pereira, V. G. L. Souza, C. G. Otoni, G. P. Camilloto and N. F. F. Soares, Food Packaging and Shelf Life, 2016, 9, 69-78.

49 G. Cimò, J. Kucerik, A. E. Berns, G. E. Schaumann, G. Alonzo and P. Conte, Environ. Sci. Technol., 2014, 62, 1912-1918.

50 S. Mubarik, A. Saeed, M. M. Athar and M. Iqbal, J. Ind. Eng. Chem., 2016, 33, 115-121.

51 A. Mashayekh-salehi, G. Moussavi and K. Yaghmaeian, Chem. Eng. J., 2017, 310, 157-169.

52 V. A. Alvarez, R. A. Ruseckaite and A. Vázquez, J. Thermoplast. Compos. Mater., 2007, 20, 291-303.

53 A. R. F. Moraes, Desenvolvimento de materiais biodegradáveis de amido termoplástico, acetato de celulose e poli (adipato co-tereftalato de butileno) por extrusão termoplástica, PhD thesis, Universidade Federal de Viçosa, Viçosa, 2015.

54 X. L. Shen, J. M. Wu, Y. Chen and G. Zhao, Food Hydrocolloids, 2010, 24, 285-290.

55 B. K. Biswas, K. Inoue, K. N. Ghimire, S. Ohta, H. Harada, K. Ohto and H. Kawakita, J. Colloid Interface Sci., 2007, 312, 214-223.

56 T. L. Eberhardt, S.-H. Min and J. S. Han, Bioresour. Technol., 2006, 97, 2371-2376.

57 C. Namasivayam and D. Sangeetha, J. Colloid Interface Sci., 2004, 280, 359-365.

58 X. P. Liao, Y. Ding, B. Wang and B. Shi, Ind. Eng. Chem. Res., 2006, 45, 3896-3901.

59 A. S. Bashammakh, J. Mol. Liq., 2016, 220, 426-431.

60 T. L. Eberhardt, S. Min and J. S. Han, Bioresour. Technol., 2006, 97, 2371-2376.

61 B. Zhao, X. Huang, X. Wu, L. Wang, A. Liu, Z. Zhang, J. Li, Z. Yu and T. Xu, Desalin. Water Treat., 2018, 116, 39-48.

62 Z. Wu, D. Gao and N. Liu, Water Qual. Res. J. Can., 2017, 52, 187-195. 